\title{
Distribution of aggA and aafA gene sequences among Escherichia coli isolates with genotypic or phenotypic characteristics, or both, of enteroaggregative $E$. coli
}

\author{
WALDIR P. ELIAS*†, SÉRGIO SUZART*, LUIZ R. TRABULSI†, JAMES P. NATARO $\ddagger$ and TÂNIA A. \\ T. GOMES* \\ * Departamento de Microbiologia, Imunologia e Parasitologia, Universidade Federal de São Paulo, Escola \\ Paulista de Medicina, †Laboratório Especial de Microbiologia, Instituto Butantan, São Paulo, Brazil and $\$$ Center \\ for Vaccine Development, University of Maryland School of Medicine, Baltimore, MD 21201, USA
}

\begin{abstract}
Two types of fimbriae, designated aggregative adherence fimbria I and II (AAF/I and AAF/II) have been described in enteroaggregative Escherichia coli (EAEC) strains. These fimbriae mediate the aggregative pattern of adherence (AA) to epithelial cells. The genes encoding the structural subunit of each fimbria have been designated agg $A$ and aaf $A$, respectively. The prevalence of these genes was investigated in 155 faecal EAEC isolates that displayed AA to HeLa cells and were isolated from children in São Paulo, Brazil. Hybridisation assays with agg $A$ and aaf $A$ sequences showed that $9.7 \%$ of these isolates carried agg $A, 3.9 \%$ aaf $A$, and none hybridised with both sequences. Of the 78 isolates displaying AA that reacted with the previously described EAEC probe (CVD432), $19.2 \%$ and $7.7 \%$ hybridised with the agg $A$ and aaf $A$ probes, respectively. None of the 77 isolates displaying AA but lacking the EAEC probe sequence hybridised with either probe. These results clearly indicate that additional factors are involved in the AA phenotype in these EAEC strains.
\end{abstract}

\section{Introduction}

Enteroaggregative Escherichia coli (EAEC) is a category of diarrhoea-producing $E$. coli characterised by a distinct pattern of adhesion to epithelial cells whereby bacteria adhere to the cells and the intervening coverslip surfaces in 'stacked brick-like' aggregates [1]. EAEC have been implicated as agents of persistent diarrhoea among children in developing countries $[2,3]$ and recently have been associated with outbreaks of diarrhoea $[4,5]$. However, the pathogenesis of EAEC diarrhoea remains unclear.

An EAEC DNA probe (CVD432), consisting of a segment from the $60-\mathrm{MDa}$ plasmid of a prototype strain, has been used for the identification of EAEC strains [6]. However, lack of homology with this probe segment has been reported in some strains characterised as EAEC by the aggregative adherence (AA) phenotype [7].

Received 7 July 1998; revised version accepted 27 Sept. 1998.

Corresponding author: Dr T. A. T. Gomes

(e-mail: tatgomes.dmip@epm.br).
Two fimbriae, designated aggregative adherence fimbria I and II (AAF/I and AAF/II), have been described in EAEC isolates [8,9]. Both are plasmidencoded and are required for expression of the AA phenotype. AAF/I is a bundle-forming fimbria which has been described in EAEC strain 17-2 [8]. The $\mathrm{AAF} / \mathrm{I}$-encoding genes are localised in two unlinked regions of a 60-MDa plasmid [8]. Region 1 encodes a cluster of structural and accessory biogenesis genes and region 2 encodes AggR, a transcriptional activator which is required for fimbria expression in strain 17-2. Based on mutational analysis and protein homology data, agg $A$ has been shown to encode the major fimbrial subunit of AAF/I. AAF/II is genetically, phenotypically and morphologically distinct from $\mathrm{AAF} / \mathrm{I}$ [9]. The fimbrial subunit gene of AAF/II has been identified and designated aafA. AAF/II confers adherence to human intestinal cells by EAEC strain 042 [9], which has been shown to elicit diarrhoea in human volunteers [10].

There are no data available describing the prevalence of $\mathrm{AAF} / \mathrm{I}$ and $\mathrm{AAF} / \mathrm{II}$ in a large number of EAEC isolates from a single epidemiological study. Therefore, the aim of this study was to evaluate the 
distribution of $\operatorname{agg} A$ and aafA genes among EAEC isolates from children with diarrhoea and age-matched controls in São Paulo, Brazil.

\section{Materials and methods}

\section{EAEC isolates}

For this study, 155 EAEC isolates, previously isolated and identified in a case-control study of 200 children with acute diarrhoea and 200 age-matched controls 1 4 years old were selected (TAT Gomes, unpublished observations). These children attended the emergency room of Hospital Infantil Menino Jesus, which is a municipal hospital that provides medical assistance to children of low socio-economic status in the city of São Paulo, Brazil. All isolates displayed AA in the HeLa cell adherence assay [11] and 78 of them reacted with the EAEC probe [6].

\section{DNA hybridisation}

AggA and aafA genes were detected by nucleotide probe hybridisation. The $\operatorname{agg} A$ probe was prepared by PCR with plasmid DNA extracted from strain 17-2 as template and the following oligonucleotides, as described by Savarino et al. [8]: SJS5-GCGTTAGAAAGACCTCCAATA and SJS6-GCCGGATCCTTAAA AATTAATTCCGGC. PCR cycling conditions were: initial denaturation at $94^{\circ} \mathrm{C}$ for $1 \mathrm{~min}$, followed by 30 cycles of denaturation at $94^{\circ} \mathrm{C}$ for $1 \mathrm{~min}$, annealing at $55^{\circ} \mathrm{C}$ for $1 \mathrm{~min}$, and extension at $72^{\circ} \mathrm{C}$ for $1 \mathrm{~min}$. These oligonucleotides amplify a product corresponding to the $\operatorname{agg} A$ gene of AAF/I. The aaf $A$ probe consisted of the 1.7-kb EcoRI fragment of pJC2 [9]. This fragment comprises aafA and part of an upstream gene encoding an AAF/II-specific fimbrial chaperone. DNA probe fragments were radiolabelled and used in colony blot assays as described previously [11].

\section{Results}

The results obtained in this study are summarised in Table 1. Only $21(13.5 \%)$ of the 155 EAEC isolates hybridised with either aggA $(9.7 \%)$ or aafA $(3.9 \%)$

Table 1. Distribution of aggA and aafA among EAEC faecal isolates from children $1-4$ years old in São Paulo, Brazil

\begin{tabular}{lccc}
\hline & & \multicolumn{2}{c}{$\begin{array}{c}\text { Number (\%) of strains } \\
\text { reacting with }\end{array}$} \\
\cline { 3 - 4 } $\begin{array}{l}\text { Adherence/reaction } \\
\text { with EAEC probe }\end{array}$ & $\begin{array}{c}\text { Total strains } \\
\text { studied }\end{array}$ & $\operatorname{aggA^{*}}$ & aaf $A^{\dagger}$ \\
\hline $\mathrm{AA} /+$ & 78 & $15(19.2)$ & $6(7.7)$ \\
$\mathrm{AA} /-$ & 77 & 0 & 0 \\
Total & 155 & $15(9.7)$ & $6(3.9)$ \\
\hline
\end{tabular}

AA, aggregative adherence to HeLa cells.

*aggA probe, AAF/I structural subunit gene.

${ }^{\dagger}$ aafA probe, AAF/II structural subunit gene. probes and none with both. AAF/I and AAF/II genes were found exclusively among EAEC probe-positive isolates.

Of 78 isolates displaying $\mathrm{AA}$ and reacting with the EAEC probe $(\mathrm{AA} /+), 19.2 \%$ and $7.7 \%$ hybridised with the $\operatorname{agg} A$ and aaf $A$ probes, respectively. None of the 77 isolates displaying AA but lacking the EAEC probe sequence $(\mathrm{AA} /-)$ hybridised with either probe.

\section{Discussion}

The aggA and aafA genes were found in $9.7 \%$ and $3.9 \%$, respectively, of 155 EAEC faecal isolates from children 1-4 years old in São Paulo, Brazil. Czeczulin et al. [9] studied 51 EAEC strains by colony blot hybridisation and also found that $\mathrm{AAF} / \mathrm{I}$ was more frequent than AAF/II. However, in that study the incidence of each gene sequence (aggA 31\%, aafA $12 \%$ ) among all strains was higher than that obtained in the present study. In this study none of the EAEC isolates that lacked homology with the EAEC probe reacted with either $\operatorname{agg} A$ or aafA probes; similar findings were reported by Czeczulin et al. [9].

EAEC are apparently similar to enterotoxigenic $E$. coli (ETEC) and require a large number of different colonisation factors [7]. The prevalence of various colonisation factors of ETEC displays geographical variation, which may also be the case among EAEC.

Interestingly, all aaf $A$ positive isolates hybridised with the diffusely adherent $E$. coli (DAEC) probe (data not shown). This probe represents a part of the daaC gene, an accessory gene required for synthesis of the F1845 fimbria [12]. This finding suggests a genetic relatedness between the accessory genes of F1845 and AAF/II. This has been confirmed in sequence analysis of the AAF/II biogenesis loci (JP Nataro, unpublished observations).

These results clearly indicate that additional fimbrial or non-fimbrial adhesins, or both, may be involved in the AA phenotype in the population studied. Other studies have demonstrated by electron microscopy [7] the presence of several different fimbriae on the surface of EAEC strains, but only AAFs have been characterised at the genetic level $[8,9]$. The role of $\mathrm{AAF} / \mathrm{I}$ and $\mathrm{AAF} / \mathrm{II}$ in diarrhoeal disease remains unclear. The involvement of AAF/II in intestinal colonisation has been suggested by the aaf $A$ mutant which no longer adheres to human intestine in tissue culture [9] and an AAF/II-producing strain that causes diarrhoea in volunteers [10]. Thus, the possibility exists that AAF/II-producing strains may be more virulent in man. Epidemiological studies should be conducted in other geographical areas to provide a broader epidemiological analysis of these adhesins in the pathogenesis of EAEC-associated diarrhoea. 
This work was supported by grants from Fundação de Amparo à Pesquisa do Estado de São Paulo (FAPESP), Conselho Nacional de Desenvolvimento Científico e Tecnológico (CNPq), Coordenadoria de Aperfeiçoamento de Pessoal de Nível Superior (CAPES), and Financiadora de Estudos e Projetos do Ministério de Ciência e Tecnologia - Programa de Apoio a Núcleos de Excelência (FINEP/ MCT/Pronex).

\section{References}

1. Nataro JP, Kaper JB, Robins-Browne R, Prado V, Vial P, Levine MM. Patterns of adherence of diarrheagenic Escherichia coli to HEp-2 cells. Pediatr Infect Dis J 1987; 6: 829-831.

2. Bhan MK, Raj P, Levine $\mathrm{MM}$ et al. Enteroaggregative Escherichia coli associated with persistent diarrhea in a cohort of rural children in India. $J$ Infect Dis 1989; 159: 1061-1064.

3. Cravioto A, Tello A, Navarro A et al. Association of Escherichia coli HEp-2 adherence patterns with type and duration of diarrhoea. Lancet 1991; 337: 262-264.

4. Cǒbeljić M, Miljković-Selimović B, Paunović-Todosijević D et al. Enteroaggregative Escherichia coli associated with an outbreak of diarrhoea in a neonatal nursery ward. Epidemiol Infect 1996; 117: 11-16.

5. Itoh Y, Nagano I, Kunishima M, Ezaki T. Laboratory investigation of enteroaggregative Escherichia coli O untypeable:H10 associated with a massive outbreak of gastrointestinal illness. J Clin Microbiol 1997; 35: 2546-2550.

6. Baudry B, Savarino SJ, Vial P, Kaper JB, Levine MM. A sensitive and specific DNA probe to identify enteroaggregative Escherichia coli, a recently discovered diarrheal pathogen. $J$ Infect Dis 1990; 161: 1249-1251.

7. Nataro JP, Kaper JB. Diarrheagenic Escherichia coli. Clin Microbiol Rev 1998; 11: 142-201.

8. Savarino SJ, Fox P, Yikang D, Nataro JP. Identification and characterization of a gene cluster mediating enteroaggregative Escherichia coli aggregative adherence fimbria I biogenesis. $J$ Bacteriol 1994; 176: 4949-4957.

9. Czeczulin JR, Balepur S, Hicks $\mathrm{S}$ et al. Aggregative Adherence fimbria II, a second fimbrial antigen mediating aggregative adherence in enteroaggregative Escherichia coli. Infect Immun 1997; 65: 4135-4145.

10. Nataro JP, Yikang D, Cookson S et al. Heterogeneity of enteroaggregative Escherichia coli virulence demonstrated in volunteers. $J$ Infect Dis 1995; 171: 465-468.

11. Gomes TAT, Blake PA, Trabulsi LR. Prevalence of Escherichia coli strains with localized, diffuse, and aggregative adherence to HeLa cells in infants with diarrhea and matched controls. $J$ Clin Microbiol 1989; 27: 266-269.

12. Bilge SS, Clausen CR, Lau W, Moseley SL. Molecular characterization of a fimbrial adhesin, F1845, mediating diffuse adherence of diarrhea-associated Escherichia coli to $\mathrm{HEp}-2$ cells. J Bacteriol 1989; 171: 4281-4289. 